\title{
UNA NUEVA ESPECIE DE THOMPSONELLA (CRASSULACEAE) DEL ESTADO DE GUERRERO, MEXICO ${ }^{1}$
}

\author{
Martha Gual Diaz \\ Laboratorio de Biogeografía \\ Departamento de Biología \\ Facultad de Ciencias, UNAM \\ 04510 México, D.F. \\ Susana Peralta Gomez \\ Laboratorio de Plantas Vasculares \\ Departamento de Biología, \\ Facultad de Ciencias, UNAM \\ 04510 México, D.F. \\ Y \\ Emmanuel Perez-Calix \\ Instituto de Ecología, A.C. \\ Centro Regional del Bajío \\ Apartado postal 386 \\ 61600 Pátzcuaro, Michoacán
}

\section{RESUMEN}

A partir de material colectado en la región de Xochipala, Guerrero, se describe, ilustra y propone como nueva para la ciencia a Thompsonella xochipalensis. La nueva especie difiere de las ya conocidas por presentar un tallo de 8 a $22 \mathrm{~cm}$ de largo y de 4.5 a $5.5 \mathrm{~mm}$ de diámetro y las hojas de la roseta son ensiformes, de 1.5 a $6.5 \mathrm{~cm}$ de largo y de 2.5 a $5.5 \mathrm{~mm}$ de ancho.

Se discute de manera parcial la distribución y la taxonomía del género Thompsonella; se presenta un cuadro en el que se comparan sus especies, así como una clave artificial para su determinación.

\section{ABSTRACT}

Thompsonella xochipalensis is described, illustrated and proposed as a new species, based on plants collected in the region of Xochipala, Guerrero. The new species differs from previously known

${ }_{1}$ Trabajo realizado con apoyo económico del Instituto de Ecología, A.C. (cuenta 902-03), del Consejo Nacional de Ciencia y Tecnología y de la Comisión Nacional para el Conocimiento y Uso de la Biodiversidad. 
species in having a caudex 8 to $22 \mathrm{~cm}$ long and 4.5 to $5 \mathrm{~mm}$ thick, and ensiform rosette leaves 1.5 to $6.5 \mathrm{~cm}$ long and 2.5 to $5.5 \mathrm{~mm}$ wide.

The distribution and taxonomy of the genus Thompsonella are partially discussed. The species of the genus are compared in a table and distinguished in an artificial key.

El género Thompsonella (Crassulaceae) es endémico al centro de México; se distribuye principalmente en la cuenca del Río Balsas, en los estados de Guerrero, México, Michoacán, Morelos, Oaxaca y Puebla. Fue propuesto por N. L. Britton y J. N. Rose en 1909, quienes incluyeron en él dos especies, T. minutiflora y T. platyphylla. La primera había sido descrita por el mismo Rose (Britton y Rose, 1903) bajo el nombre de Echeveria minutiflora; sin embargo, Charles Henry Thompson, quien tuvo bajo cultivo la planta, observó que tanto la inflorescencia como las flores no correspondían a las del género Echeveria, y así lo dio a conocer a Britton y a Rose, quienes en agradecimiento le dedicaron el nombre del nuevo taxon. La segunda especie, descrita en el mismo artículo, fue colectada en 1907 por C. G. Pringle y floreció en 1908. De acuerdo con Kimnach (1993), ambas plantas pueden ser incluidas en una misma especie, correspondiéndole el nombre de T. minutiflora (Rose) Britt. et Rose.

Thompsonella pertenece a la subfamilia Echeverioideae por poseer hojas suculentas, arrosetadas, inflorescencia lateral, flores pentámeras, con los pétalos unidos en la base y erectos en la mitad inferior. De acuerdo con Moran (1992), este género está estrechamente relacionado con Graptopetalum, del que se distingue por su inflorescencia densa, alargada y estrecha de flores sésiles, sin fragancia notable, estambres erectos y estilos largos.

Desde la publicación de Britton y Rose (1909) no se dieron a conocer otros elementos para el grupo, hasta que Moran (1992) describió T. colliculosa de la región oriental del estado de Michoacán, y un año más tarde Kimnach (1993) dio a conocer T. spathulata del Cañón (Valle) de Tomellín, en el estado de Oaxaca.

La planta que se describe a continuación fue colectada durante las exploraciones ligadas al estudio florístico de la región de Xochipala, Guerrero. Al tratar de identificarla se encontró que pertenece al género Thompsonella; sin embargo, se observó que el hábito, así como la forma y el tamaño de sus hojas y brácteas no corresponden a los descritos para las especies conocidas del género, por lo que se propone como nueva para la ciencia bajo el siguiente nombre:

Thompsonella xochipalensis Gual, Peralta et Pérez-Calix sp. nov. (Fig. 1).

Planta suffruticosa, glabra; caules 8-22 cm longi, simplices, decumbentes, dependentes vel erecti; folia lineari-lanceolata, anguste lanceolata usque ad ensiformia, 1.5-6.5 longa, 0.25-0.55 cm lata, apice acuta; inflorescentia spiciformis vel paniculata; bracteae linearilanceolatae, anguste lanceolatae vel ensiformes, 15-25 mm longae, 2-3 mm latae, apice acutae; flores 6-8 mm diametro ; sepala anguste lanceolata, 3.5-4 mm longa, 1.5-2 mm lata.

Planta sufruticosa, glabra, de 5 a $40 \mathrm{~cm}$ de alto (incluyendo la inflorescencia); tallos de 8 a $22 \mathrm{~cm}$ de largo y de 4.5 a $5.5 \mathrm{~mm}$ de diámetro cerca de la base, no ramificados, decumbentes, colgantes o erectos, de color grisáceo, suculentos; hojas sésiles, alternas, 
Gual et al.: Una Nueva Especie de Thompsonella del Estado de Guerrero
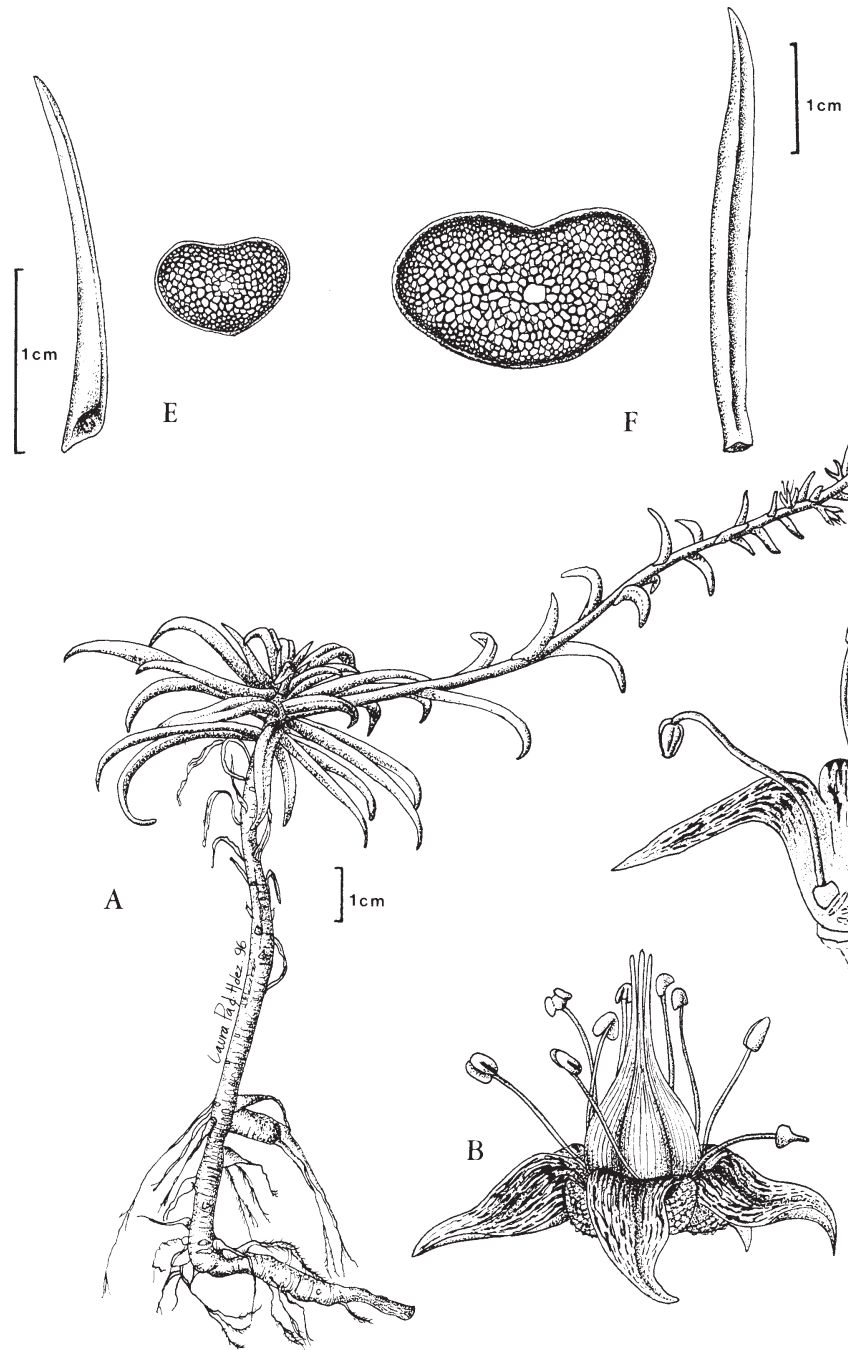

C
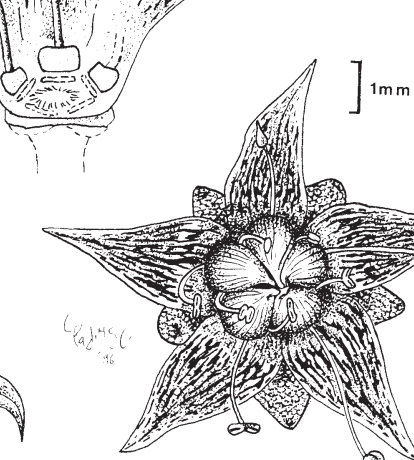

$\mathrm{D}$

Fig.1. Thompsonella xochipalensis sp. nov. A. Hábito. B. Flor vista lateralmente. C. Flor mostrando nectarios y estambres. D. Vista superior de la flor. E. Bráctea vista lateralmente y en corte tranversal. F. Hoja vista ventralmente y en corte transversal (basado en S. Peralta y M. Gual 49).

formando una roseta apical densa, estrechamente lanceoladas a ensiformes en contorno, de 1.5 a $6.5 \mathrm{~cm}$ de largo y de 0.25 a $0.55 \mathrm{~cm}$ de ancho, acanaladas dorsalmente, ápice agudo, base truncada, glabras, ligeramente farinosas en la juventud, suculentas, de color 
verde olivo, con manchas rojizas en la base; inflorescencias laterales, de 16 a $33 \mathrm{~cm}$ de largo, en forma de espigas, principalmente en la porción superior, o bien, paniculadas con las ramas en cincino con 2 a 3 flores en cada ramificación; pedúnculo erecto o colgante; brácteas alternas, estrechamente lanceoladas a ensiformes, de 1.5 a $2.5 \mathrm{~cm}$ de largo y de 2 a $3 \mathrm{~mm}$ de ancho, ápice agudo, base espolonada; flores de 6 a $8 \mathrm{~mm}$ de diámetro; cáliz de 5 sépalos libres, angostamente lanceolados, de 3.5 a $4.0 \mathrm{~mm}$ de largo y de 0.8 a $1.0 \mathrm{~mm}$ de ancho, ápice agudo, base redondeada, densamente farinosos, acanalados dorsalmente, de color verde, rojizos en la base; corola de 5 pétalos connados en la base, extendidos o reflexos en la parte media, elípticos, de 5.5 a $6.0 \mathrm{~mm}$ de largo y de 1.5 a $2.0 \mathrm{~mm}$ de ancho, ápice acuminado, base atenuada, pruinosos, el haz glauco con líneas rojizas, el envés glauco, farinoso; estambres 10, filamentos filiformes, de ca. $5.5 \mathrm{~mm}$ de largo, blancos; anteras bitecas, elipsoides, de ca. $0.5 \mathrm{~mm}$ de largo, rojizas, blancas en dehiscencia; nectarios 5, blancos, de ca. $0.7 \mathrm{~mm}$ de largo y ca. $0.8 \mathrm{~mm}$ de ancho; gineceo apocárpico, 5-carpelar, ovarios piriformes, blancos, pruinosos, glabros; placentación axilar, de 16 a 18 óvulos por carpelo; estilo de ca. $2 \mathrm{~mm}$ de largo, estigma inconspicuo; folículos piriformes, erectos, de ca. $6.5 \mathrm{~mm}$ de largo y de ca. $1 \mathrm{~mm}$ de ancho, semillas piriformes.

TIPO: México, Guerrero, municipio Eduardo Neri, 2 km al SE de Xochipala, Barranca Xoxocoapa, alt. $950 \mathrm{~m}$. Ladera caliza con vegetación de bosque tropical caducifolio, 29.IX.1990, S. Peralta y M. Gual 49 (holotipo IEB, isotipo MEXU).

Material adicional consultado: Guerrero, municipio Eduardo Neri, Barranca Acatitlán, $5 \mathrm{~km}$ al NE de Xochipala, 2.X.1990, M. Gual y S. Peralta 167.

Distribución: T. xochipalensis crece formando pequeñas poblaciones en laderas calizas, con suelo pedregoso-arcilloso, a una altitud de 950-1050 m. El clima de la región es cálido-subhúmedo y la vegetación corresponde al bosque tropical caducifolio de Agonandra racemosa, Bursera chemapodicta, Neobuxbaumia mezcalensis y Plumeria rubra, entre otros árboles.

La nueva especie se conoce únicamente de dos localidades, que distan entre sí por aproximadamente ocho kilómetros, en la misma región.

Fenología: El período de floración se inicia en septiembre, extendiéndose hasta finales de octubre.

Etimología: El epíteto específico se ha asignado con referencia al poblado de Xochipala, en cuyas proximidades se ha colectado la planta.

Los datos presentados en el cuadro 1 manifiestan que las semejanzas morfológicas entre las especies de Thompsonella son pocas. Así, T. xochipalensis difiere de las demás por su tallo más desarrollado, generalmente mayor de $10 \mathrm{~cm}$ de largo, hojas y brácteas estrechamente lanceoladas, linear-lanceoladas a ensiformes, muy diferentes de las que presentan las otras especies. La clave que se propone a continuación nos auxilia para separar los componentes conocidos del género. 
Gual et al.: Una Nueva Especie de Thompsonella del Estado de Guerrero

Cuadro 1. Caracteres morfológicos distitintivos de las especies de Thompsonella, su época de floración, así como su distribución geográfica.

\begin{tabular}{|c|c|c|c|c|}
\hline & T. xochipalensis & T. spathulata & T. minutiflora & T. colliculosa \\
\hline \multicolumn{5}{|l|}{ TALLO } \\
\hline Largo $(\mathrm{cm})$ & $8-22$ & $<2$ & $<3$ & ca. 8 \\
\hline Diámetro $(\mathrm{cm})$ & $0.45-0.55$ & ca. 0.6 & ca. 0.5 & $0.9-1.3$ \\
\hline \multicolumn{5}{|l|}{ HOJA } \\
\hline Forma & $\begin{array}{l}\text { linear-lanceolada, } \\
\text { estrechamente } \\
\text { lanceolada o } \\
\text { ensiforme }\end{array}$ & $\begin{array}{l}\text { fuertemente } \\
\text { espatulada }\end{array}$ & $\begin{array}{c}\text { elíptica a } \\
\text { oblanceolada o } \\
\text { estrechamente } \\
\text { obovada }\end{array}$ & $\begin{array}{l}\text { elíptico-oblan- } \\
\text { ceolada }\end{array}$ \\
\hline Largo $(\mathrm{cm})$ & $1.5-6.5$ & ca. $4(-5)$ & $2-10$ & $10-27$ \\
\hline Ancho $(\mathrm{cm})$ & $0.25-0.55$ & $\begin{array}{l}\text { 1-2 (cerca del } \\
\text { ápice) }\end{array}$ & $1-2.5$ & $3.5-7$ \\
\hline Apice & agudo & cuspidado & $\begin{array}{l}\text { agudo a } \\
\text { redondeado }\end{array}$ & agudo \\
\hline \multicolumn{5}{|l|}{ BRACTEA } \\
\hline Forma & $\begin{array}{l}\text { linear-lanceolada, } \\
\text { estrechamente } \\
\text { lanceolada a } \\
\text { ensiforme }\end{array}$ & $\begin{array}{c}\text { obovada a } \\
\text { linear-obovada }\end{array}$ & oblanceolada & oblanceolada \\
\hline Largo $(\mathrm{cm})$ & $1.5-2.5$ & $0.5-1.5$ & $0.5-1.5$ & ca. 3 \\
\hline Ancho & $0.2-0.3$ & $0.3-0.8$ & $0.2-0.25$ & ca. 1.5 \\
\hline Apice & agudo & cuspidado & agudo & $?$ \\
\hline $\begin{array}{l}\text { Epoca de } \\
\text { floración }\end{array}$ & $\begin{array}{l}\text { septiembre- } \\
\text { octubre }\end{array}$ & $?$ & $\begin{array}{l}\text { agosto- } \\
\text { diciembre }\end{array}$ & enero \\
\hline $\begin{array}{l}\text { Distribución } \\
\text { conocida }\end{array}$ & Gro. & Oax. & $\begin{array}{l}\text { Gro., Méx., } \\
\text { Mor., Oax., } \\
\text { Pue. }\end{array}$ & Mich. \\
\hline
\end{tabular}

1 Hojas y brácteas linear-lanceoladas, estrechamente lanceoladas o ensiformes

1 Hojas y brácteas espatuladas, elíptico-oblanceoladas o estrechamente obovadas. 
2 Hojas espatuladas con el ápice cuspidado ............................................. T. spathulata

2 Hojas elíptico-oblanceoladas o estrechamente obovadas con el ápice agudo a redondeado

3 Hojas mayores de $10 \mathrm{~cm}$ de largo y $3.5 \mathrm{~cm}$ de ancho, con el ápice agudo; tallo de hasta $8 \mathrm{~cm}$ de largo. Plantas conocidas de Michoacán ................. T. colliculosa

3 Hojas menores de $10 \mathrm{~cm}$ de largo y $3 \mathrm{~cm}$ de ancho; plantas acaulescentes o con un tallo de menos de $3 \mathrm{~cm}$ de largo. Plantas conocidas de Guerrero, México, Morelos, Oaxaca y Puebla T. minutiflora

\section{AGRADECIMIENTOS}

Los autores manifestamos nuestra gratitud al Dr. Jerzy Rzedowski R. por la revisión crítica al manuscrito, así como por la traducción de la diagnosis al latín; al Biól. Sergio Zamudio y al Dr. José Luis Villaseñor Ríos por sus acertadas sugerencias al trabajo, a la Biól. Laura Padilla Hernández por la elaboración de la ilustración y al Sr. Charles Glass por auxiliarnos en la consecusión de literatura.

\section{LITERATURA CITADA}

Britton, N. L. y J. N. Rose. 1903. New or noteworthy North American Crassulacae. Bull. New York Bot. Gard. 3: 1-45.

Britton, N. L. y J. N. Rose. 1909. Thompsonella, a new genus of Crassulaceae from México. Contr. U.S. Natl. Herb. 12: 91-392.

Kimnach, M. 1993. Thompsonella spathulata, a new species from Oaxaca. Cact. Succ. Journ. (U.S.) 65: 41-43.

Moran, R. 1992. Thompsonella Britton \& Rose (Crassulaceae), with T. colliculosa, a new species. Cact. Succ. Journ. (U.S.) 64: 37-44. 